\title{
A novel technique in the management of refractory variceal bleeding
}

Acute esophageal variceal bleeding is a complication with high morbidity and mortality, causing $70 \%$ of upper gastrointestinal bleeding in patients with liver disease [1]. The first-line treatment of bleeding combines the use of vasoactive drug therapy, endoscopic band ligation, and prophylactic antibiotic administration, following initial hemodynamic resuscitation efforts [2]. Around 10\%-20\% of cases are refractory to conventional therapy, necessitating alternative therapies for hemorrhagic control [1]. Among the rescue therapies for variceal hemorrhage are the traditional use of balloon tamponade and transjugular intrahepatic portosystemic shunt (TIPS). The current use of a self-expanding metal stent (SEMS) has also been utilized as a new option for refractory bleeding [3].

We describe the case of a 52-year-old man with cirrhosis secondary to primary biliary cholangitis, who was admitted because of an episode of upper gastrointestinal hemorrhage 5 days after an elective variceal ligation session ( $\triangleright$ Video 1 ). On endoscopic evaluation, massive bleeding was diagnosed ( $\mathbf{F i g . 1}$ a) and a Sengstaken-Blakemore balloon was placed. At review 12 hours later, a further endoscopy was performed for bal-

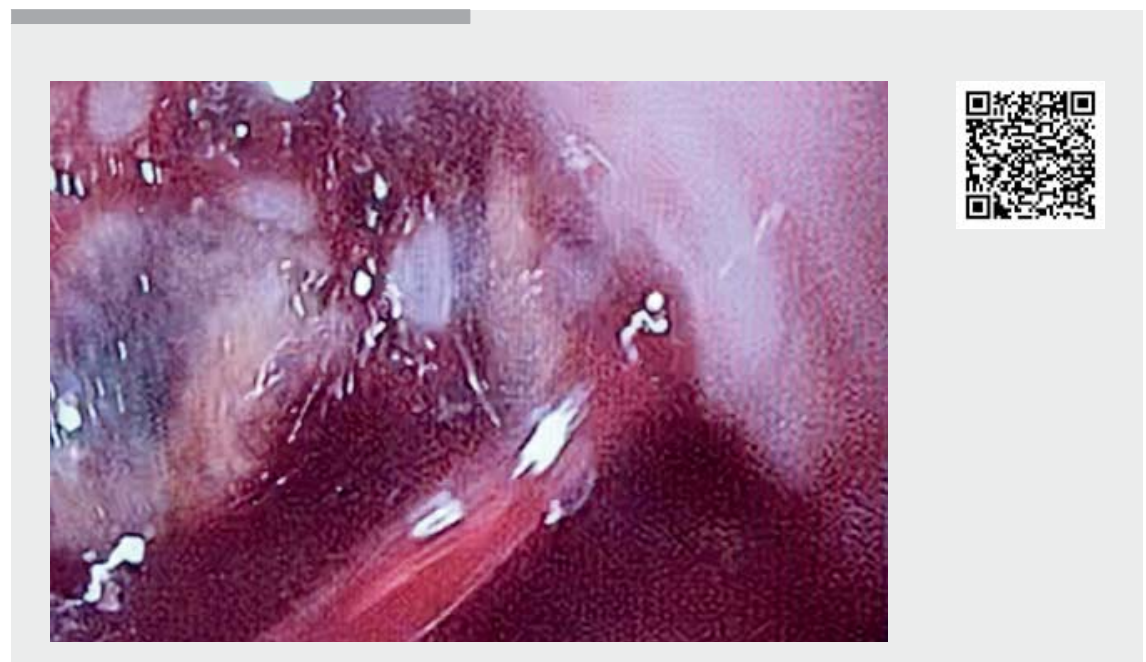

Video 1 Video showing a patient with extensive bleeding after elective ligation of esophageal varices, who underwent placement of a Sengstaken-Blakemore balloon to control bleeding. After removal of the balloon, the patient continued to have active bleeding and we chose to use a self-expanding metal stent (SX-ELLA Danis) to stop the bleeding. After 5 days of this stent being in place, the patient underwent transjugular intrahepatic portosystemic shunt (TIPS) with no further evidence of bleeding. After 10 days of hospitalization, the patient died because of kidney damage.

Ioon removal. During balloon removal, active bleeding was observed ( $>$ Fig. 1 b) and a covered esophageal SEMS (SX-ELLA Danis, Czech Republic) was placed. After stent placement, successful hemostasis was achieved ( $\mathbf{F i g . 1} \mathbf{c}$ ). After 5 days of stent placement, the patient underwent TIPS ( $\triangleright$ Fig. 2 ), and no new episodes of bleeding were observed (\Fig. $\mathbf{3}$ ).

With a substantial patient population who fail to respond to conventional medical therapy and band ligation, a variety of
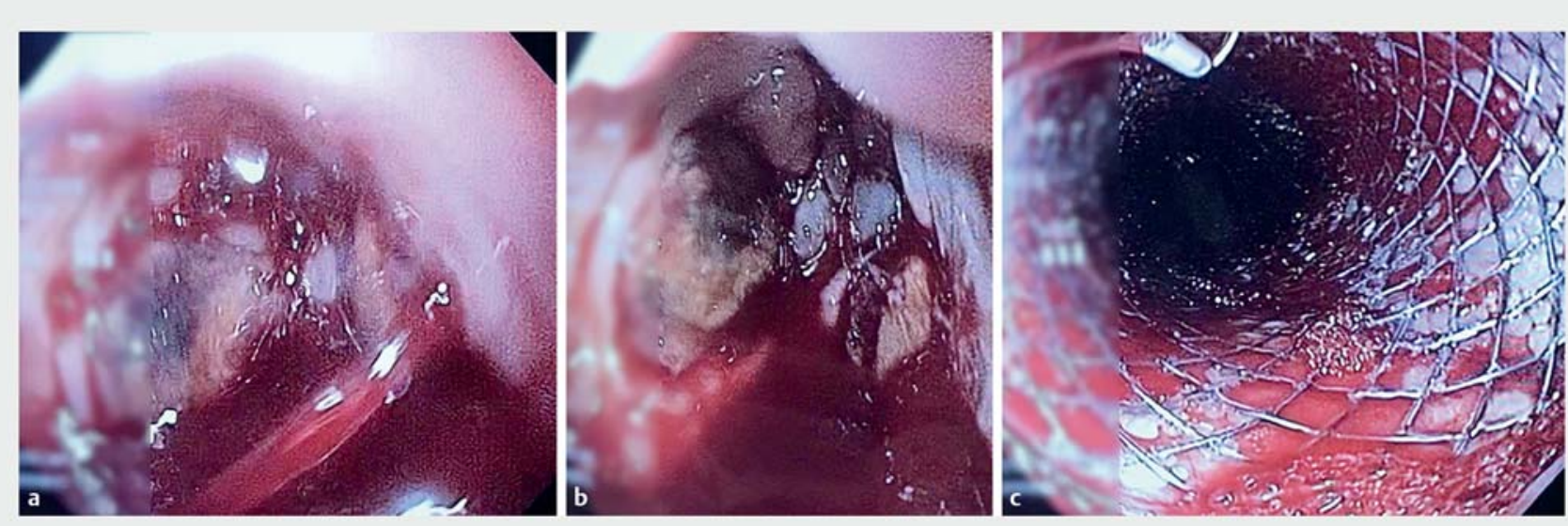

Fig. 1 Endoscopic views showing: a massive variceal bleeding in the esophagus; $\mathbf{b}$ active bleeding after removal of the Sengstaken-Blakemore balloon; c no further evidence of bleeding after use of a self-expanding covered esophageal metal stent. 


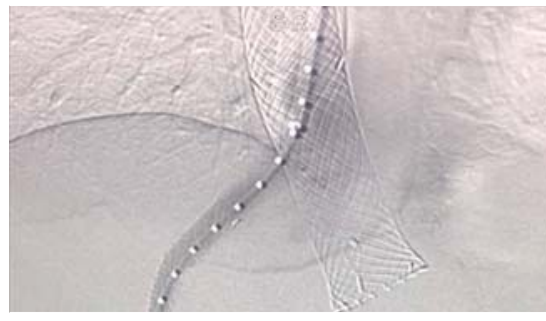

- Fig. 2 Radiographic image showing the transjugular intrahepatic portosystemic shunt and the previously place esophageal stent.

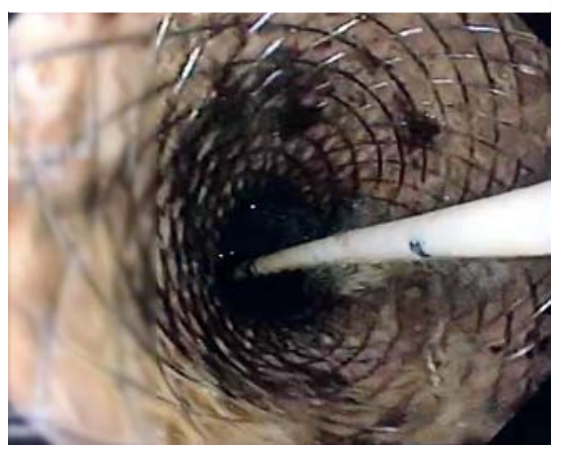

- Fig. 3 Endoscopic evaluation 5 days after stent placement showing no evidence of bleeding.

potential alternative therapies have been established. The stent used in our patient is specifically produced for controlling variceal bleeding and has a mean withdrawal time of 14 days. On this occasion, after 10 days of hospitalization, our patient died of kidney injury with the stent in place. The technical success rate of deploying this stent in patients with acute variceal bleeding is $96.7 \%$ [4], and it should be considered for use in patients with refractory bleeding. Stent placement is relatively safe with fewer complications than balloon tamponade, with both suitable as bridging therapy [5].

Endoscopy_UCTN_Code_TTT_1AO_2AD

\section{Competing interests}

E. de Moura is a consultant for Boston Scientific and Olympus.

The authors

Gustavo Oliveira Luz, Sérgio Eiji Matuguma, Antonio Coutinho Madruga Neto, Igor Braga Ribeiro, Fernanda Dal Bello, Diogo Turiani Hourneaux de Moura, Eduardo Guimarães Hourneaux de Moura

Gastrointestinal Endoscopy Unit, Hospital das

Clínicas da Faculdade de Medicina da

Universidade de São Paulo, São Paulo, Brazil

\section{Corresponding author}

Eduardo Guimarães Hourneaux de Moura, MD, PhD

Gastrointestinal Endoscopy Unit, University of São Paulo Medical School, Oscar Freire 2250 conj. 316, Bairro Cerqueira César, São Paulo, 05409-012, Brazil eduardoghdemoura@gmail.com

\section{References}

[1] Escorsell À, Pavel O, Cárdenas A et al. Esophageal balloon tamponade versus esophageal stent in controlling acute refractory variceal bleeding: A multicenter randomized, controlled trial. Hepatology 2016; 63: 1957-1967

[2] Ribeiro IB, Rezende DT, Madruga Neto AC et al. Endoscopic dual therapy for giant peptic ulcer hemorrhage. Endoscopy 2018; 50: E316-E317

[3] Lôbo MRA, Chaves DM, de Moura DTH et al. Safety and efficacy of EUS-guided coil plus cyanoacrylate versus conventional cyanoacrylate technique in the treatment of gastric varices: a randomized controlled trial. Arq Gastroenterol 2019. doi:10.1590/500042803.201900000-08

[4] Shao X-D, Qi X-S, Guo X-Z. Esophageal stent for refractory variceal bleeding: a systemic review and meta-analysis. Biomed Res Int 2016; 2016: 4054513
[5] Maiwall R, Jamwal KD, Bhardwaj A et al. SX-Ella Stent Danis effectively controls refractory variceal bleed in patients with acute-on-chronic liver failure. Dig Dis Sci 2018; 63: 493-501

\section{Bibliography}

DOI https://doi.org/10.1055/a-1027-6241

Published online: 15.11.2019

Endoscopy 2020; 52: 310-311

(c) Georg Thieme Verlag KG

Stuttgart · New York

ISSN 0013-726X

\section{ENDOSCOPY E-VIDEOS}

https:/|eref.thieme.de/e-videos

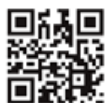

Endoscopy E-Videos is a free access online section, reporting on interesting cases and new

techniques in gastroenterological endoscopy. All papers include a high quality video and all contributions are freely accessible online.

This section has its own submission website at https://mc.manuscriptcentral.com/e-videos 